\title{
HERBIVORIA EM FLORAS GONDUÂNICAS DO NEOPALEÓZOICO DO RIO GRANDE DO SUL: ANÁLISE QUANTITATIVA
}

\author{
KAREN ADAMI-RODRIGUES, PAULO ALVES DE SOUZA, ROBERTO IANNUZZI \\ \& IRAJÁ DAMIANI PINTO
}

Depto. de Paleontologia e Estratigrafia, UFRGS, 91540-970, Cx. P. 15001, Porto Alegre, RS, Brasil. gerarus@hotmail.com,roberto.iannuzzi@ufrgs.br,paulo.alves.souza@ufrgs.br,ipinto@ufrgs.br

\begin{abstract}
RESUMO - A análise quantitativa de 16.291,29 cm² de superfície foliar de 352 espécimes da "Flora Glossopteris" coletados na Formação Rio Bonito (Artinskiano/Kunguriano da bacia do Paraná) revelou que 8,24\% destes foram atacados por insetos herbívoros. Os valores das áreas herbivorizadas e das áreas preservadas foram utilizados na obtenção, por táxon e afloramento, da proporção da área removida por herbivoria e do índice de herbivoria, cujos resultados variam entre $0,24-2,97 \%$ e $0,25-2,95 \%$, respectivamente. Folhas notófilas de glossopterídeas, especialmente do morfo-gênero Glossopteris, foram os tipos foliares mais atacados, seguidos de megáfilos de Cordaites. Nas três localidades estudadas (afloramentos de Quitéria, Mina do Faxinal e Mina do Morro do Papaléo), os diferentes índices de herbivoria detectados permitiram estabelecer relações entre as paleofloras e os paleoambientes deposicionais associados, além de comparações com os padrões das floras modernas. Entre os paleoambientes identificados, os de vegetação desenvolvida em área pantanosa, margem de corpos lacustres e de planície de inundação foram os únicos que apresentaram indícios de herbivoria.
\end{abstract}

Palavras-chave: Paleoartropodologia, herbivoria, análise quantitativa, Permiano, Flora Glossopteris, bacia do Paraná.

ABSTRACT - HERBIVORY ON GONDWANA FLORAS OF THE NEOPALEOZOIC OF RIO GRANDE DO SUL STATE: QUANTITATIVE ANALYSIS. The quatitative analysis of $16,291.29 \mathrm{~cm}^{2}$ of foliar surface of 352 specimens of the "Flora Glossopteris" recorded from the Rio Bonito Formation (Artinskian/Kungurian of the Paraná basin) revealed that $8,24 \%$ of the leaves were attacked by herbivorous insects. The values of foliar herbivorized and preserved areas were utilized to obtain, by taxa and outcrop, the proportion of herbivorized removed area and the herbivory index, whose results range between $0.24-2.97 \%$ and $0.25-2.95 \%$ respectively. Notophylls of glossopterids were the most attacked of the foliar types, in special the morphogenus Glossopteris followed by the megaphylls of Cordaites. Different rates of herbivory were found from the three outcrops studied (Quitéria, Faxinal Quarry and Morro do Papaléo Quarry) and suggested relationship between the paleofloras and the associated depositional paleoenvironments as well as comparison with current herbivory standards. Among the identified paleoenvironments, the ones developed in swampy areas, lacustrine margins and inundation plains were the only ones presenting signs of herbivory.

Key words: Palaeoarthropodology, herbivory, quantitative analysis, Permian, Glossopteris Flora, Paraná basin.

\section{INTRODUÇÃO}

A análise do registro das interações entre insetos e plantas fósseis é um campo novo da paleontologia, recebendo maior atenção na última década. Praticamente, toda a literatura sobre o tema consiste em descrições das interações de insetos extintos com plantas fósseis, acrescidas de significativas hipóteses sobre co-evolução (e.g., Scott \& Taylor, 1983; Labandeira \& Beall, 1990; Chaloner et al., 1991; Scott, 1992; Scott et al., 1992, 1994; Stephenson \& Scott, 1992).

A maioria dos estudos sobre interação inseto-planta é qua- litativa, concentrada nas evidências dos danos causados às plantas vasculares, bem como nos mecanismos de formação de traços fósseis e na atribuição taxonômica em termos paleobotânicos e/ou entomológicos (e.g., Scott et al., 1992).

No âmbito gondvânico, as contribuições sobre o tema ainda são escassas, referentes a registros de evidências de fitofagia no Permiano da Índia (Srivastava, 1987) e do Brasil (Guerra-Sommer, 1995), com considerações sobre suas relações paleoecológicas e paleoambientais.

Adami-Rodrigues et al. (no prelo), detalhando o trabalho desenvolvido em Adami-Rodrigues (2003), identificaram 11 ti- 
pos de evidências de interação inseto-planta em material da "Flora Glossopteris" proveniente dos depósitos da Formação Rio Bonito no Estado do Rio Grande do Sul: 1) atividade alimentar externa de folhagem contínua; 2) atividade alimentar de bordo foliar descontínuo; 3) atividade alimentar de ápice foliar; 4) remoção de limbo foliar-tipo ovóide; 5) remoção de limbo foliar-tipo linear; 6) mina linear; 7) mina em Y; 8) esqueletonização; 9) pequenas incisões relacionadas a perfuração-sugação; e, 10) galha E 11) ovoposição de libélula. Para os autores, a preferência dos insetos fitófagos neopaleozóicos (i.e., protortópteros, homópteros e coleópteros) nas floras analisadas foi pelas folhas do tipo Glossopteris (G. brasiliensis Guerra-Sommer 1988, G. cf. communis Feistmantel 1876, G. occidentalis White 1908, G. cf. indica Schimper 1809, G. browniana Brongniart 1828), Cordaites hislopii (Bunbury) Seward \& Leslie Gangamopteris obovata (Carruthers) White 1908, com resultados diferenciados quantos aos tipos de danos presentes em cada táxon. Embora os tipos de interação sejam diversificados, verifica-se certa monotonia entre floras de diferentes contextos paleobiogeográficos (Euroamérica versus Gondwana), tendo como base de comparação os tipos descritos por Beck \& Labandeira (1998) para uma flora tropical do Permiano do Texas, E.U.A.
Por sua vez, os estudos quantitativos se fazem importantes para a determinação da amplitude e da freqüência dos tipos de interação, permitindo estabelecer relações ambientais a partir de parâmetros comuns. As primeiras abordagens sobre os métodos de análise quantitativa foram realizadas por Scott et al. (1994) e Beck et al. (1996). Posteriormente, Beck \& Labandeira (1998) introduziram os cálculos da proporção da área removida por herbivoria e do índice de herbivoria, aplicados ineditamente em floras fósseis paleozóicas norte-americanas, de modo a permitir o estabelecimento de comparações com as taxas de herbivoria nas florestas atuais e subsidiar as inferências paleoecológicas.

O presente trabalho constitui-se na primeira tentativa de quantificação das áreas herbivorizadas para material do Neopaleozóico da bacia do Paraná, a partir de estudo qualitativo prévio (Adami-Rodrigues et al., no prelo) realizado em localidades da Formação Rio Bonito e da Formação Irati/Serra Alta no Estado do Rio Grande do Sul (Figura 1). A aplicação do método quantitativo é restrita aos espécimes coletados em diferentes níveis estratigráficos de três afloramentos da Formação Rio Bonito no Estado do Rio Grande do Sul. Além disso, introduz-se um refinamento das informações sobre herbivorização a fim de permitir avanços nas interpretações tafonômicas e paleoambientais.

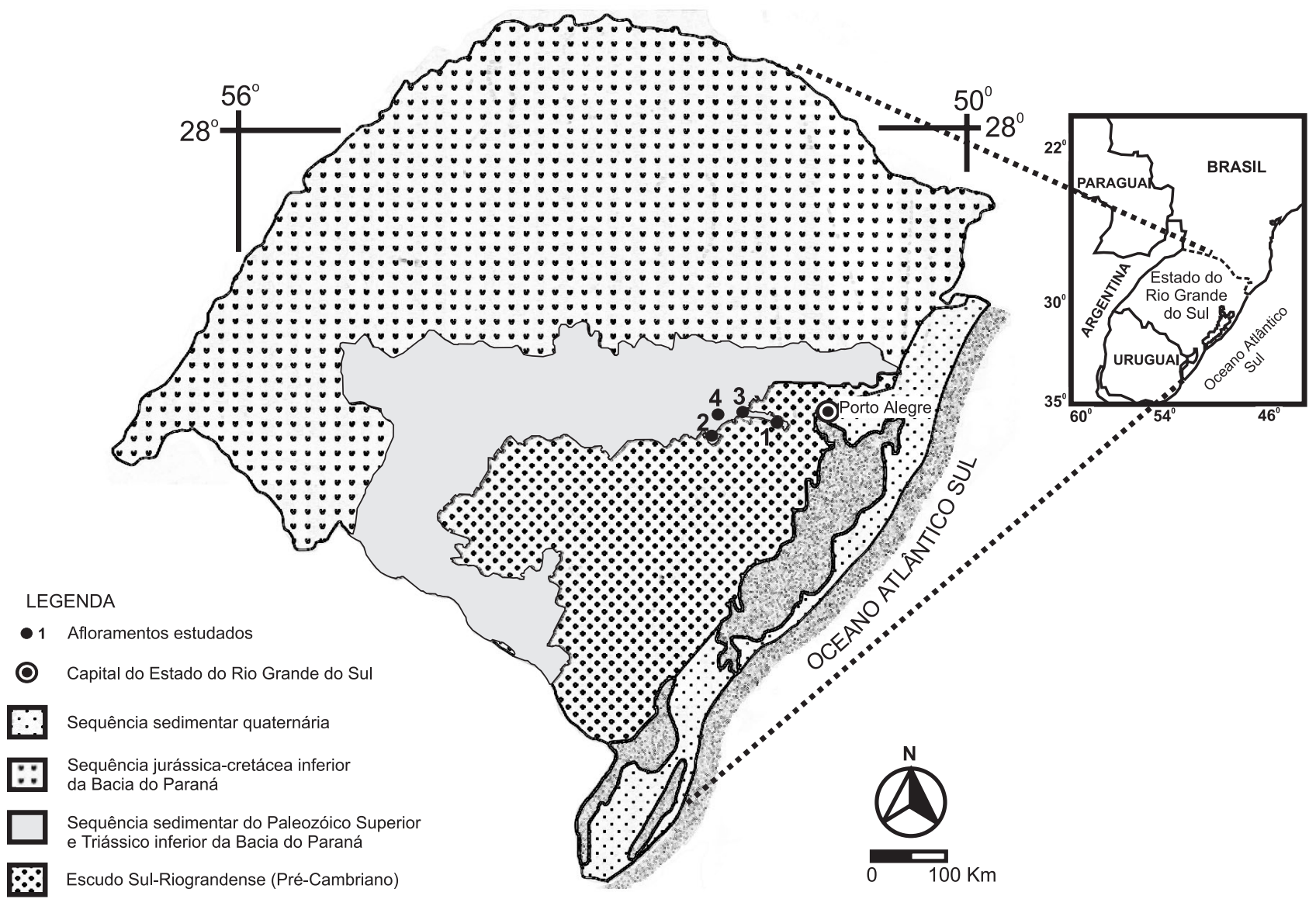

Figura 1. Mapa geológico do Estado do Rio Grande do Sul, com a localização dos afloramentos estudados: mina do Morro do Papaléo (1), mina do Faxinal (2), Quitéria (3), e estrada BR-290, município de Minas do Leão (4).

Figure 1. Geological map of State of the Rio Grande do Sul showing geographic setting of the Morro do Papaléo quarry (1) and Faxinal quarry (2), and Quitéria (3) and highway BR-290 outcrop, near Minas do Leão town (4). 


\section{CONTEXTOGEOLÓGICOEPALEONTOLÓGICO}

A área estudada está inserida no contexto do grande ciclo transgressivo/regressivo neopaleozóico da bacia do Paraná, denominado "Superseqüência Gondwana I" por Milani (1997), representado pelos depósitos dos grupos Tubarão (Permo-Carbonífero) e Passa Dois (Permiano). A sequência sedimentar do Subgrupo Itararé (base do Grupo Tubarão) é constituída por termos essencialmente clásticos, associados a ambientes marinhos, transicionais e continentais, relacionados, em grande parte, à glaciação permocarbonífera gondvânica. A sucessão pós-glacial é representada pelas unidades do Subgrupo Guatá que, no sul da bacia, são materializadas pelas formações Rio Bonito, na base, e Palermo, no topo, com fácies, respectivamente, flúviodeltaicas/estuarinas e marinhas. Por último, as unidades do Grupo Passa Dois (i.e., formações Irati, Serra Alta, Teresina e Rio do Rastro) apresentam litologias variadas, associadas a sistemas deposicionais relacionados ao contínuo aquecimento e continentalização a que estiveram sujeitos os centros de deposição durante grande parte do final do Permiano.

A espessura média da Formação Rio Bonito no Estado do Rio Grande do Sul é de 70 m, sendo essencialmente constituída por pacotes arenosos, pelitos carbonosos e camadas de carvão, relacionados a sistemas de planície costeira e continentais que foram seguidos por sistemas marinhos. Grande parte de seus depósitos tem sido interpretada como correspondente a ambientes fluviais, lacustres, deltaicos, estuarinos, com influência de marés e de plataforma (shoreface e offshore) (e.g., Lavina \& Lopes, 1987; Albuquerque \& Lopes, 1990; Netto, 1994; Holz, 1998), que se estabeleceram na Bacia do Paraná no Eopermiano (Artinkiano/Kunguriano). Macrofitofósseis e palinomorfos são os fósseis mais abundantes (e.g., Marques-Toigo, 1988; Guerra-Sommer \& Cazzulo-Klepzig, 1993).

Em termos gerais, o registro fóssil do neopaleozóico da bacia do Paraná é bastante diversificado, incluindo vegetais, animais (vertebrados e invertebrados) e palinomorfos. A sucessão florística é inicialmente representada por elementos pré-glossopterídeos, ocorrentes, principalmente, nas porções inferior e média do Subgrupo Itararé. A partir do topo desta unidade, ocorrem os primeiros registros dos elementos que caracterizam a "Flora Glossopteris", com significativa abundância e diversificação da flora a partir dos níveis carbonosos da Formação Rio Bonito até a Formação Rio do Rastro, topo do Grupo Passa Dois. Insetos fósseis foram registrados em várias localidades do Subgrupo Itararé e da Formação Irati (ou Serra Alta) e são representados por prothortopterídeos, protodonatas, blatóides, paraplecopterídeos, homopterídeos, neuropterídeos, coleopterídeos e mecopterídeos. Uma síntese sobre as ocorrências paleobotânicas e paleoentomológicas relacionadas à Formação Rio Bonito é apresentada em AdamiRodrigues \& Iannuzzi (2001).

\section{MATERIAIS}

Os níveis fossilíferos estudados são relativos à porção média da Formação Rio Bonito, procedentes de três localida- des aflorantes no Rio Grande do Sul: mina do Faxinal, mina do Morro do Papaléo e Quitéria (Figura 1).

A mina do Faxinal está localizada no município de Arroio dos Ratos, aproximadamente $50 \mathrm{~km}$ a sudoeste do município de Guaíba (coordenadas UTM 6.651.500 mN, 432.700 $\mathrm{mE})$. As amostras estudadas são procedentes de pelitos carbonosos associados diretamente aos carvões, cuja origem é interpretada como de planície aluvial (Guerra-Sommer, 1988).

A mina do Morro do Papaléo situa-se no município de Mariana Pimentel, que faz limite a leste com o município de Guaíba (coordenadas UTM 6.620.000 mN, 490.000 mE). As amostras do nível inferior 4 (Biofácies A de Vieira \& Iannuzzi, 2000) são relativas a siltitos esbranquiçados interpretados como de margem de corpo lacustre (Iannuzzi et al., 2003). Aquelas dos níveis superiores 7 e 8 (Biofácies D de Vieira \& Iannuzzi, 2000) são constituídas por argilitos siltosos associados à planície de inundação de um sistema fluvial anastomosado (Iannuzzi et al., 2003).

O afloramento de Quitéria está localizado no município de Pantano Grande (52²2'W, 30²8'S). As amostras são provenientes de siltitos e argilitos escuros associados a pelitos carbonosos (Biofácies E de Piccoli et al., 1991), cuja origem é interpretada como de sistema laguna-barreira (Jasper \& Guerra-Sommer, 1999).

Um total de 352 espécimes de folhas foi estudado, preservadas na forma de impressões e/ou compressões carbonificadas. Dentre estas, 43 apresentam 11 tipos diferenciados de interação inseto/planta (Adami-Rodrigues et al., no prelo), dos quais 29 correspondem a processos de herbivoria. Os tipos de herbivoria considerados no presente estudo limitaram-se a cinco categorias: 1) atividade alimentar externa de folhagem contínua; 2) atividade alimentar de bordo foliar descontínuo; 3) atividade alimentar de ápice foliar; 4) remoção de limbo foliar - tipo ovóide; 5) remoção de limbo foliar tipo linear, ilustradas na Figura 2 (incluindo um análogo atual em 2C).

A análise taxonômica prévia permitiu a identificação de associações compostas por folhas de glossopterídeas (Glossopteris brasiliensis, G. browniana, G. cf. communis, G. occidentalis, G. cf. indica, Gangamopteris obovata) e cordaiteanas (Cordaites hislopii). O material estudado está depositado na coleção de paleobotânica do Departamento de Paleontologia e Estratigrafia do Instituto de Geociências da Universidade Federal do Rio Grande do Sul, sob a sigla $\mathrm{MP}-\mathrm{Pb}$.

\section{MÉTODOS DE ANÁLISE QUANTITATIVA}

Os 352 espécimes estudados foram mensurados a partir da delimitação de suas áreas preservadas e da reconstituição de seus contornos foliares nas áreas com herbivoria. Os contornos foliares, obtidos em papel vegetal com auxílio de câmara clara, foram digitalizados e tratados no programa de processamento de imagens UTHSCSA Image Tool, disponibilizados pelo The University of Texas Health Science Center, fornecendo os valores das áreas de superfície foliar preservada $(\mathrm{P})$, as respectivas 

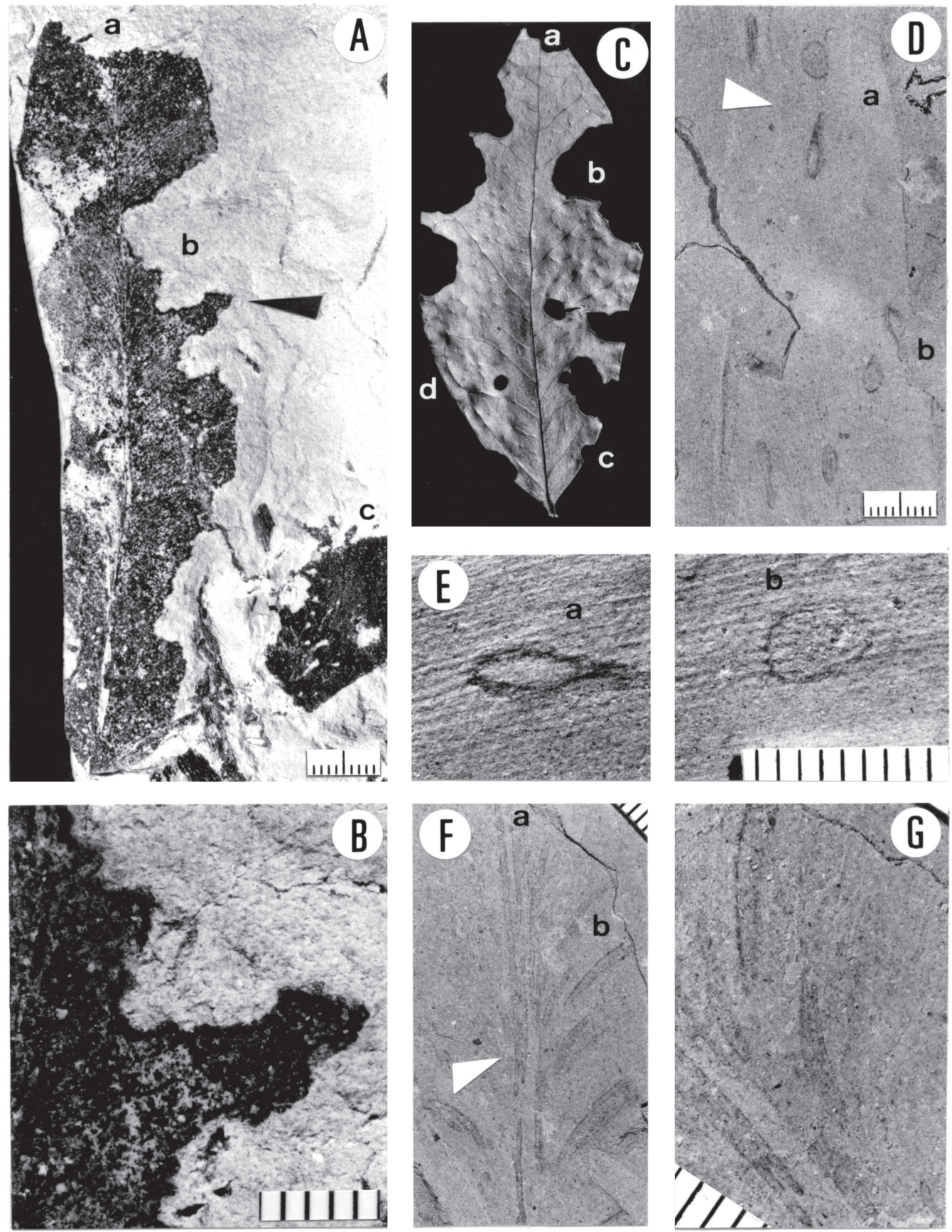

Figura 2. Evidência de alimentação externa de margem foliar e remoção total de limbo em folhas de glossopterídeas e cordaiteanas. A. Alimentação externa de ápice (a) e de margem foliar (b) em Glossopteris sp. (Pb-2796a), e de remoção total de limbo (c) em possível bráctea de glossopterídea, ambos mostrando tecido de reação marginal (indicado pela seta). B. Detalhe da área atacada indicada por seta em A, mostrando proeminente tecido de reação ao longo da margem foliar danificada. C. Exemplos de tipos de danos causados por hebivoria em folha de angiosperma atual; (a) atividade alimentar de ápice foliar, (b) atividade contínua em margem foliar, (c) atividade descontínua em margem foliar, (d) remoção total de limbo. D. Remoção total de limbo (a) e alimentação descontínua em margem foliar (b) em Cordaites hislopii (Pb-3655A), mostrando tecido de reação marginal desenvolvido (seta). E. Detalhe da área atacada indicada por seta em D, mostrando cavidades de alimentação de formato elipsoidal (a) a ovóide (b). F. Remoção total de limbo intervenal em Glossopteris cf. communis (Pb-3655E), mostrando cavidades de alimentação entre a venação central (a) e a secundária (b). G. Detalhe das cavidades alimentares indicadas por seta em $\mathrm{F}$ (escalas milimétricas).

Figure 2. Evidence of foliar margin and hole feeding on glossopterid and cordeatean leaves. A. Apical (a) and continuous margin-feeding (b) on Glossopteris sp. (Pb-2796a), and hole-feeding (c) on glossopterid bract, showing reaction tissue rim at arrow. B. Enlargement of margin-feeding area arrow of $\mathrm{A}$, showing prominent reaction tissue rim. C. Examples of plant-insect interactions on modern angiosperm leave; (a) feeding activity of foliar apex, (b) continuous activity of the foliar edge, (c) discontinuous activity of the foliar margin, (d) holefeeding. D. Hole- (a) and discontinuous margin-feeding (b) on Cordaites hislopii ( $\mathrm{Pb}-3655 \mathrm{~A}$ ), showing developed reaction tissue rim at arrow. E. Enlargement of hole-feeding area arrow of D, showing ellipsoidal (a) to ovoid (b) shape of feedings holes. F. Interveinal holefeeding on Glossopteris cf. communis (Pb-3655E), showing feeding holes between midrid (a) and secondary (b) veins. G. Enlargement of hole-feeding area arrow of $\mathrm{F}$ (scale bars in millimeters). 
áreas herbivorizadas projetadas $(\mathrm{H})$ e as áreas totais de cada espécime $(\mathrm{T}=\mathrm{P}+\mathrm{H})$. A somatória das áreas totais $(\mathrm{ST})$ dos 352 espécimes corresponde a $16.291,29 \mathrm{~cm}^{2}\left(1,629 \mathrm{~m}^{2}\right)$.

As dimensões das áreas totais $(\mathrm{T})$ e respectivas áreas herbivorizadas $(\mathrm{H})$, por espécime foliar, constituem os parâmetros utilizados para os cálculos da proporção da área removida por herbivoria e do índice de herbivoria, método empregado em floras fósseis por Beck \& Labandeira (1998). Os valores de proporção da área removida por herbivoria foram obtidos a partir da seguinte fórmula: área herbivorizada projetada por folha $(\mathrm{H})$, área total por folha $(\mathrm{T}) * 100(\mathrm{em} \%)$. Os valores do índice de herbivoria são assim obtidos: média da área herbivorizada projetada por folha $(\mathrm{H})$, média da área total por folha $(\mathrm{T}) * 100(\mathrm{em} \%)$. A Figura 3 ilustra as áreas consideradas nesses cálculos em um espécime aleatório, ressaltando área total $\mathrm{T}=\mathrm{P}+\mathrm{H}$ em Figura $3 \mathrm{C}$.

Os valores considerados e os produtos obtidos em cada um desses dois cálculos, por táxon e por nível estratigráfico, são apresentados na Tabela 1, onde também são mostrados a proporção das folhas herbivorizadas, os cálculos totais por nível estratigráfico, os cálculos totais por afloramento e os cálculos gerais de todas as associações estudadas. Os pro- cedimentos estão de acordo com os métodos de estimativa visual, tratamento de imagem e cálculos propostos e aplicados por Beck \& Labandeira (1998) e Scott \& Titchener (1999).

Como apoio à análise quantitativa, os 29 espécimes herbivorizados foram agrupados em cinco das sete classes de dimensões foliares propostas por Ash et al. (1999), considerando as áreas reconstituídas: nanófila $\left(25-225 \mathrm{~mm}^{2}\right)$, micrófila (225-2,025 mm²), notófila $\left(2,025-4,500 \mathrm{~mm}^{2}\right)$, mesófila $(4,500-$ $\left.18,225 \mathrm{~mm}^{2}\right)$ e megáfila (> 164,025 mm²), da menor para a maior.

\section{RESULTADOS}

\section{Caracterização dos danos}

A análise qualitativa de fitofagia revelou onze tipos de danos causados na flora do Neopaleozóico da bacia do Paraná, que sugeriu maior preferência dos insetos fitófagos pelas glossopterídeas e, subordinadamente e mais especificamente (em termos de tipo de dano), pelas folhas de Cordaites hislopii e Gangamopteris obovata. A análise quantitativa de herbivoria do material da Formação Rio Bonito está restrita aos cinco tipos identificados como atividade alimentar de folhagem externa, assim descritos (Adami-Rodrigues et al., no prelo):

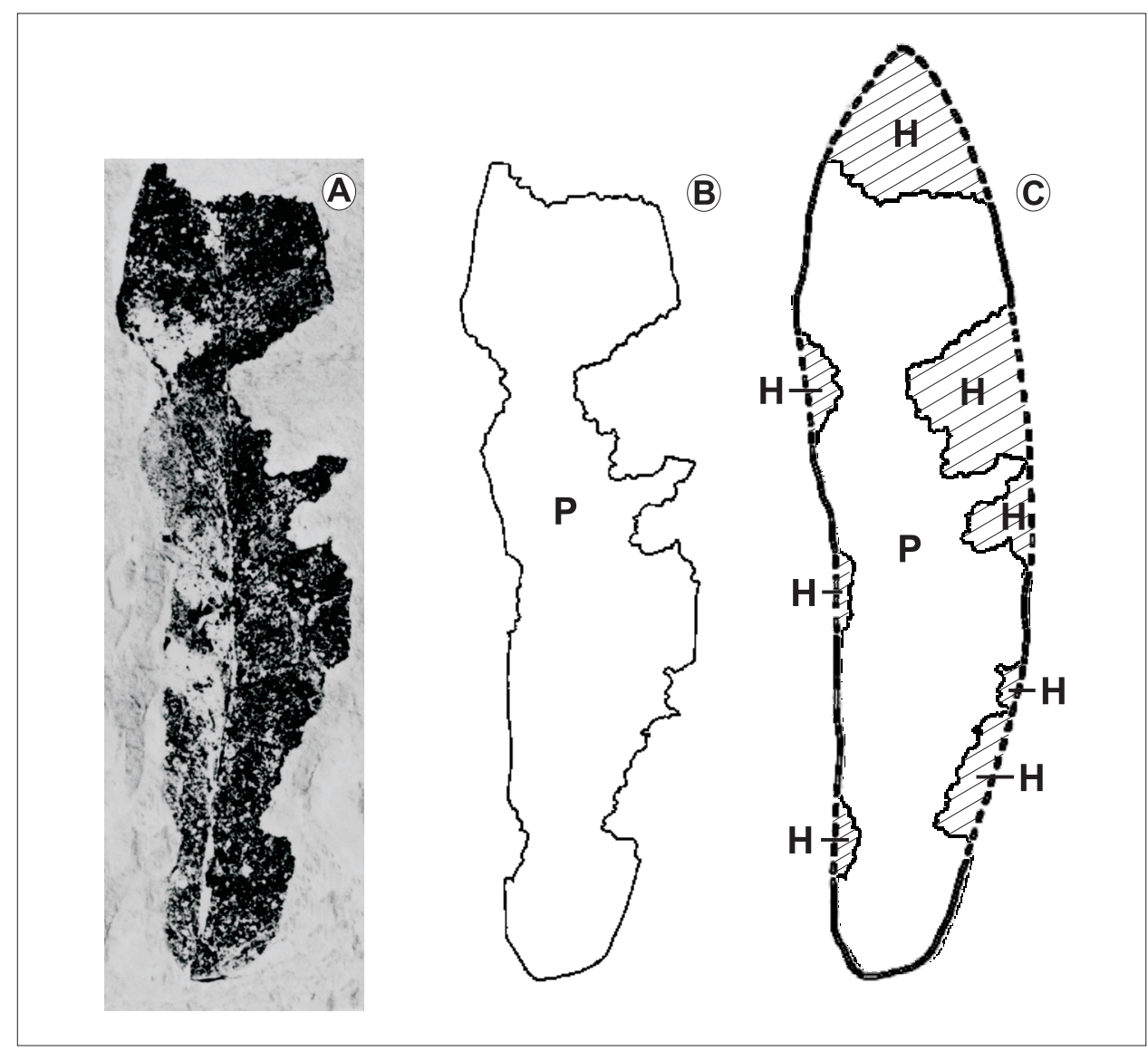

Figura 3. Método para obtenção das áreas utilizadas no cálculo da proporção da área removida por herbivoria e do índice de herbivoria, a partir de um espécime de Glossopteris cf. communis (MP-Pb 2796a). A. Compressão foliar herbivorizada. B. Contorno da folha herbivorizada em $A$, onde se vê a área original preservada $(P)$. C. Reconstituição da folha herbivorizada em $A$, a partir do contorno obtido em $B$, e projeção da área herbivorizada, hachurada $(H)$, e a área total $T=(P+H)$.

Figure 3. Method at area estimation used to calculate the proportion of herbivorized area removed and herbivory index, from a specimen of Glossopteris cf. communis (MP-Pb 2796a). A. Herbivorized compressed leaf. B. Foliar outline of herbivorized leaf, showing the preserved original area $(\mathrm{P})$. C. Reconstitution of herbivorized leaf shown in $A$, from previous outline given in $B$, displaying the herbivorized area $(H)$, hatched pattern, and total area $T=(P+H)$. 


\section{Atividade alimentar externa de folhagem contínua}

Descrição. Recortes largos de bordo foliar dispostos em uma sucessão contínua de retirada do bordo com contorno fortemente escurecido, evidenciando tecido de reação.

Dimensões. Extensão dos pequenos recortes contínuos de 2 $\mathrm{mm}$ a $3 \mathrm{~mm}$ em torno do bordo.

Observação. A atividade contínua de bordo foliar se registra apenas em folhas de Glossopteris sp. e Glossopteris communis, Glossopteris browniana, não ocorrendo registros em folhas de Cordaites.

\section{Atividade alimentar de bordo foliar descontínuo}

Descrição. Traços marginais interrompidos. Registro de mecanismo de defesa com evidencia clara de tecido de reação, registrada através de contorno escurecido ou colorido ao redor da área onde se deu a fitofagia.

Dimensões. $2 \mathrm{~mm}$ a $1,3 \mathrm{~cm}$ entre a venação marginal e o bordo.

Observações. Os registros em impressões da mina do Morro Papaléo apresentam o contorno correspondente ao tecido de reação determinado por coloração avermelhada, devido a presença de óxido de ferro. Já nas compressões foliares da mina do Faxinal, o tecido de reação é determinado pelo maior acúmulo de matéria orgânica (indicado por um contorno escuro), que corresponde a resquícios orgânicos alterados do próprio tecido.

\section{Atividade alimentar de ápice foliar}

Descrição. Extração contínua não superficial do ápice foliar com tecido de reação claramente definido por contorno escurecido.

Dimensões. 1,9 mm a 2 cm de extensão transversal em relação ao ápice foliar.

Observações. Este tipo de interação tem seu registro em folhas notófilas de Glossopteris cf. communis e Glossopteris brasiliensis da mina do Faxinal. Esse dano à planta é interpretado como originado a partir de pequenos orthopterídeos com partes mandibulares flexíveis e diferentes dos insetos que estariam envolvidos com a herbivoria extensiva ou contínua de bordo foliar.

\section{Remoção de limbo foliar - tipo ovóide}

Descrição. Formas ovóides a elipsoidais alongadas identificadas por tecido de reação, no qual o maior eixo da cavidade está alinhada ao sentido da venação, com a remoção do limbo foliar.

Dimensões. $3 \mathrm{~mm}$ a $6 \mathrm{~mm}$ de comprimento.

Observações. As remoções do tipo ovóide e elipsoidal alongadas são registradas apenas em Cordaites hislopii.

\section{Remoção de limbo foliar - tipo linear}

Descrição. Remoções lineares entre veias que partem da veia central, com aumento do espessamento entre a venação principal e a secundária.

Observações. As impressões foliares da mina do Morro Papaléo são pouco contrastantes, mas a preservação dos contornos onde houve o ataque está demarcada pela pre- sença de óxido de ferro e de uma irregularidade singular que indicam a presença anterior de um tecido de reação.

\section{Dados quantitativos}

Foram identificadas três classes de dimensões foliares nos 29 espécimes herbivorizados: notófila (15 espécimes), mesófila (3) e megáfila (11). Dentre os espécimes de Glossopteris, 15 são notófilos, dois são mesófilos e um megáfilo. Todas as folhas do tipo Cordaites são megáfilas e uma única Gangamopteris analisada é mesófila.

Em Quitéria, somente dois espécimes do morfo-gênero Glossopteris apresentaram herbivoria, não sendo detectados danos nas folhas associadas do tipo Gangamopteris e Cordaites. Os dois espécimes representam $7,41 \%$ das folhas analisadas e fornecem índice de herbivoria de $2,95 \%$. Individualmente, os exemplares apresentam índices de herbivoria de $17,90 \%$ e $33,17 \%$, respectivamente. Esses valores são considerados altos e sua análise indica uma herbivoria localizada (apenas dois espécimes em 27), relativamente intensa e específica ao morfo-gênero Glossopteris.

No afloramento da mina do Faxinal, a amostragem e a área da superfície total de folhas no morfo-gênero Glossopteris são significativamente bem maiores do que em Cordaites. No entanto, a proporção de folhas herbivorizadas para os dois gêneros é equivalente, o que permite melhor comparação. Embora o índice de herbivoria em Glossopteris seja aparentemente baixo $(0,50 \%)$, corresponde a mais de três vezes o valor observado em Cordaites $(0,15 \%)$. É dessa localidade, o espécime que apresenta individualmente o maior índice de herbivoria (49,03\%), correspondendo a uma folha da morfo-espécie Glossopteris cf. communis (MP-Pb 2796).

Do afloramento da mina do Morro do Papaléo, os dados foram tratados separadamente para o nível 4 (inferior na seqüência) e níveis 7 e 8 (superiores na seqüência). No primeiro nível, foi detectada herbivoria apenas em Glossopteris (= G. cf. communis), correspondendo a um índice de 3,31\%. Por outro lado, todos os morfo-genêros em análise dos níveis 7 e 8 apresentaram herbivoria. Cordaites hislopii é o táxon que mais se destacou em termos do índice de herbivoria para estes níveis superiores. O índice aparentemente baixo $(0,93 \%)$ em Cordaites é relativamente maior que os dos morfo-gêneros Glossopteris $(0,13 \%)$ e Gangamopteris $(0,25 \%)$, em cerca de 7 e 4 vezes, respectivamente. A proporção de folhas herbivorizadas, em nível de morfo-gênero, é também maior para Cordaites, atingindo 26,67\% do total de 30 espécimes analisados dos níveis 7 e 8 . Por sua vez, o morfo-gênero Glossopteris apresentou valores de índice de herbivoria e na proporção de folhas herbivorizadas muito baixos $(0,13 \%$ e $4,12 \%$, respectivamente) nesses níveis. Dentre as morfo-espécies de Glossopteris, G. cf. communis é a que registra maior índice de herbivoria $(0,25 \%)$ e de proporção de folhas herbivorizadas $(7,89 \%)$.

Considerando todos os afloramentos analisados, a proporção de folhas herbivorizadas entre as distintas associações pode ser considerada muito próxima, com mínimo de 
Tabela 1. Valores e base de cálculo para a proporção de área removida por herbivoria, índice de herbivoria e proporção de folhas herbivorizadas para as associações da Formação Rio Bonito. Abreviaturas: T, área da superfície total; H, área herbivorizada.

Table 1. Date base to estimation of the proportion of herbivorized area removed and herbivory index and proportion of herbivorized leaves for the floral assemblages from the Rio Bonito Formation of Rio Grande do Sul, southern Brazil. Abbreviations: T, original surface area; H, herbivorized area.

\begin{tabular}{|c|c|c|c|c|c|c|c|c|c|}
\hline \multirow[b]{2}{*}{ Parâmetros para cálculo } & \multirow[b]{2}{*}{$\begin{array}{l}\mathrm{n}^{\circ} . \text { de } \\
\text { espé- } \\
\text { cimes }\end{array}$} & \multirow[b]{2}{*}{$\begin{array}{c}\text { Espéci- } \\
\text { mes } \\
\text { herbivo- } \\
\text { rizados }\end{array}$} & \multicolumn{3}{|c|}{$\begin{array}{l}\text { Proporção da área } \\
\text { removida por herbivoria }\end{array}$} & \multicolumn{4}{|c|}{ Índice de herbivoria } \\
\hline & & & $\mathrm{T}\left(\mathrm{cm}^{2}\right)$ & $\mathrm{H}\left(\mathrm{cm}^{2}\right)$ & $\begin{array}{c}\mathrm{H} / \mathrm{T} \\
\times 100 \\
(\%)\end{array}$ & $\begin{array}{l}\text { Média de T } \\
\text { (por folha, } \\
\mathrm{em} \mathrm{cm}^{2} \text { ) }\end{array}$ & $\begin{array}{l}\text { Média de H } \\
\text { (por folha, } \\
\mathrm{em} \mathrm{cm}^{2} \text { ) }\end{array}$ & $\begin{array}{c}\text { Propor- } \\
\text { ção de } \\
\text { folhas } \\
\text { herbivo- } \\
\text { rizadas } \\
(\%)\end{array}$ & $\begin{array}{c}\text { Média de } \\
\text { T / } \\
\text { Média de } \\
\text { H } \\
\times 100 \\
(\%)\end{array}$ \\
\hline \multicolumn{10}{|c|}{ Quitéria } \\
\hline Glossopteris angustifolia & 02 & 00 & 13,20 & 0,00 & 0,00 & 6,60 & 0,00 & 0,00 & 0,00 \\
\hline Glossopteris cf. communis & 19 & 01 & 304,75 & 6,96 & 2,28 & 16,04 & 0,37 & 5,26 & 2,31 \\
\hline Glossopteris sp. & 03 & 01 & 88,14 & 6,87 & 7,79 & 29,38 & 2,29 & 33,33 & 7,79 \\
\hline Glossopteris spp. & 24 & 02 & 406,09 & 13,83 & 3,41 & 16,92 & 0,58 & 8,33 & 3,43 \\
\hline Gangamopteris obovata & 02 & 00 & 19,96 & 0,00 & 0,00 & 9,98 & 0,00 & 0,00 & 0,00 \\
\hline Cordaites hislopii & 01 & 00 & 39,93 & 0,00 & 0,00 & 39,93 & 0,00 & 0,00 & 0,00 \\
\hline Total da localidade & 27 & 02 & 465,98 & 13,83 & 2,97 & 17,26 & 0,51 & 7,41 & 2,95 \\
\hline \multicolumn{10}{|c|}{ Faxinal } \\
\hline Glossopteris cf. communis & 01 & 01 & 35,96 & 17,63 & 49,03 & 35,96 & 17,63 & 100,00 & 49,03 \\
\hline Glossopteris browniana & 02 & 02 & 77,76 & 0,32 & 0,41 & 38,88 & 0,16 & 100,00 & 0,41 \\
\hline Glossopteris brasiliensis & 02 & 02 & 101,16 & 3,48 & 3,44 & 50,58 & 1,74 & 100,00 & 3,44 \\
\hline Glossopteris sp. & 140 & 05 & $5.874,44$ & 9,65 & 0,16 & 41,96 & 0,07 & 3,57 & 0,17 \\
\hline Glossopteris spp. & 145 & 10 & $6.089,32$ & 31,08 & 0,51 & 42,00 & 0,21 & 6,90 & 0,50 \\
\hline Cordaites hislopii & 26 & 02 & $1.414,02$ & 1,98 & 0,14 & 54,39 & 0,08 & 7,69 & 0,15 \\
\hline Total da localidade & 171 & 12 & $7.503,34$ & 33,06 & 0,44 & 43,88 & 0,19 & 7,02 & 0,43 \\
\hline \multicolumn{10}{|c|}{ Morro do Papaléo - níveis 7 e 8} \\
\hline Glossopteris cf. communis & 38 & 03 & $2.903,75$ & 7,33 & 0,25 & 76,41 & 0,19 & 7,89 & 0,25 \\
\hline Glossopteris occidentalis & 43 & 01 & $2.876,25$ & 0,73 & 0,03 & 66,89 & 0,02 & 2,33 & 0,03 \\
\hline Glossopteris cf. indica & 01 & 00 & 112,13 & 0,00 & 0,00 & 112,13 & 0,00 & 0,00 & 0,00 \\
\hline Glossopteris sp. & 15 & 00 & 243,27 & 0,00 & 0,00 & 16,22 & 0,00 & 0,00 & 0,00 \\
\hline Glossopteris spp. & 97 & 04 & $6.135,40$ & 8,06 & 0,13 & 63,25 & 0,08 & 4,12 & 0,13 \\
\hline Gangamopteris obovata & 11 & 01 & 783,43 & 2,02 & 0,26 & 71,22 & 0,18 & 9,09 & 0,25 \\
\hline Cordaites hislopii & 30 & 08 & 967,16 & 9,05 & 0,94 & 32,24 & 0,30 & 26,67 & 0,93 \\
\hline Total da localidade & 138 & 13 & $7.885,99$ & 19,13 & 0,24 & 57,14 & 0,14 & 9,42 & 0,25 \\
\hline \multicolumn{10}{|c|}{ Morro do Papaléo - nível 4} \\
\hline Glossopteris cf. communis & 10 & 2 & 313,95 & 10,42 & 3,32 & 31,40 & 1,04 & 20,00 & 3,31 \\
\hline Gangamopteris obovata & 02 & 0 & 38,18 & 0,00 & 0,00 & 19,09 & 0,00 & 0,00 & 0,00 \\
\hline Cordaites hislopii & 04 & 0 & 83,85 & 0,00 & 0,00 & 20,96 & 0,00 & 0,00 & 0,00 \\
\hline Total da localidade & 16 & 2 & 435,98 & 10,42 & 2,39 & 27,25 & 0,65 & 12,50 & 2,39 \\
\hline $\begin{array}{r}\text { Total geral de todas as } \\
\text { localidades }\end{array}$ & 352 & 29 & $16.291,29$ & 76,44 & 0,47 & 46,28 & 0,22 & 8,24 & 0,48 \\
\hline
\end{tabular}

$7,02 \%$ e máximo de $12,50 \%$. Por outro lado, os índices de herbivoria são discrepantes, com valores que variam desde 0,25\% nos níveis 7 e 8 da mina do Morro do Papaléo a 2,95\% em Quitéria, uma diferença de cerca de 12 vezes maior. De acordo com os índices, Glossopteris cf. communis é a morfoespécie mais herbivorizada.

\section{DISCUSSÃO}

Considerações sobre a ontogenia e a estrutura foliar

Para a estimativa e a análise de áreas herbivorizadas em folhas fósseis, é necessária atenção a alguns processos atuais. Muitas vezes, os herbívoros consomem uma folha- 
gem nova por inteiro. Conseqüentemente, esse tipo de herbivoria não é preservado no registro (Scott \& Titchener, 1999). Uma folha juvenil herbivorizada, ao expandir-se durante o crescimento, também expande os danos causados precocemente. Desta forma, caso a herbivoria não seja avaliada através de índices que considerem a relação entre a proporção de área herbivorizada e de área foliar preservada, pode ocorrer uma superestimativa da área removida (Landsberg \& Ohmart, 1989).

Para Wint (1983), a utilização de estimativas visuais das áreas removidas em folhas da vegetação moderna tem se mostrado um método seguro. No entanto, para as floras fósseis, a impossibilidade de acompanhamento do desenvolvimento das folhas e da verificação da extensão areal dos danos restringe essa abordagem. Além disso, o potencial de herbivoria de cada táxon pode variar quanto à adaptação do organismo indutor do dano, envolvendo particularidades ontogenéticas, físicas e químicas do hospedeiro.

Aspectos tafonômicos também influenciam as avaliações sobre a taxa de herbivoria. Folhas pequenas e grossas dos estratos arbóreos superiores em áreas florestadas atuais têm melhor potencial de fossilização do que as folhas largas e finas dos estratos médios (Fergunson, 1970; Greenwood, 1992). Essas variações são significativas na biota atual, mas de difícil observação no registro fóssil.

A preferência dos insetos por folhas notófilas de Glossopteris cf. communis pode estar relacionada ao fato de que as folhas desta espécie oferecem recursos mais nutritivos, sugerindo um grau de toxidade não limitante à ação dos insetos ou que se trata de uma espécie não tóxica. Nas folhas do tipo Cordaites, a herbivoria está restrita a folhas megáfilas, que não ofereceriam resistência química ou mecânica durante suas fases mais senis de desenvolvimento.

A remoção total de limbo foliar é encontrada, preferencialmente, em folhas de Cordaites e, raramente, em folhas de Glossopteris, sendo nestas últimas registrada apenas através da remoção entre veias. O que justifica a preferência dos herbívoros pela remoção do limbo das folhas de Cordaites em detrimento às de Glossopteris pode ser a espessura do limbo. O limbo foliar em megáfilos de Glossopteris poderia ser mais espesso do que nos de Cordaites. Uns poucos megáfilos de Glossopteris, preservados por processos autigênicos nos níveis 7 e 8 da mina do Morro do Papaléo, indicam que estes tipos foliares possuíam mesófilos espessos. Por outro lado, sabe-se que as folhas gondvânicas de Cordaites não apresentam feixes de fibras em seus mesófilos foliares, como ocorre com as registradas para a Euroamérica (McLoughlin \& Drinnan, 1996). Portanto, o limbo de Cordaites, pelo menos no Gondwana, seria mais facilmente raspado pelas mandíbulas dos insetos indutores desse tipo de dano. Esta hipótese se sustenta à medida que a remoção total de limbo é registrada em megáfilos de Cordaites e em morfo-espécies de Glossopteris com folhas menores (nanófilas e notófilas), que talvez apresentem limbos mais delgados e/ ou menos fibrosos.

\section{Processos tafonômicos e paleoambientais}

Os paleoambientes identificados com maior índice de herbivoria são os desenvolvidos ao redor de áreas pantanosas, registrados para a mina do Faxinal e para Quitéria (Guerra-Sommer, 1995; Piccoli et al., 1991) e nas margens de corpos d'água lacustres, presentes no nível 4 da mina do Morro do Papaléo (Iannuzzi et al., 2003). Estes paleoambientes, gerados em condições de baixa energia, propiciaram habitats adequados para o desenvolvimento de insetos e ofereceram melhores condições tafonômicas para o registro das interações inseto-planta. A análise tafonômica das folhas que registraram intensa herbivoria e tecidos de reação encontrados na mina do Faxinal, em Quitéria e na mina do Morro do Papaléo indica que essas folhas foram pouco transportadas; do contrário, ocorreria a fragmentação das mesmas. Deste modo, essas folhas constituem-se em um importante subsídio na interpretação da origem parautóctone das associações estudadas.

\section{CONSIDERAÇÕES FINAIS}

A quantificação das áreas foliares removidas por herbivoria exigiu a aplicação de método pioneiramente empregado em material gonduânico da bacia do Paraná. A aplicação do método mostrou-se eficiente à medida que vários padrões de intensidade, preferência e relações paleoambientais e tafonômicas puderam ser detectados.

Do total dos espécimes, 8,24\% apresentam herbivoria, com índice de herbivorização entre $0,25 \%$ e $2,95 \%$. Os dados de herbivoria nesse trabalho são divididos por taxon de plantas hospedeiras e por associação paleoflorística, verificando-se que folhas notófilas de Glossopteris (i.e., Glossopteris cf. communis) representam o tipo mais atacado nos níveis analisados da mina do Faxinal e de Quitéria e no nível 4 da mina do Morro do Papaleó, correspondendo, aproximadamente, a 3,5\% do total das folhas herbivorizadas.

Aparentemente, essas glossopterídeas eram suficientemente abundantes e nutritivas, atraindo a preferência de coleópteros, homópteros e ortópteros primitivos. Por outro lado, em Cordaites hislopii foi registrada herbivoria apenas em megáfilos, provenientes dos níveis 7 e 8 da mina do Morro do Papaléo e da seção pelítica de Quitéria. Deduz-se que as folhas menores de Cordaites (estágios juvenis?) teriam possivelmente oferecido algum tipo de defesa (química ou mecânica) à herbivoria.

As taxas de dano foliar (índice de herbivoria $=4 \%$ ) referidas por Beck \& Labandeira (1998) para gigantopterídeas de florestas riparianas do Permiano inferior do Texas, E.U.A., são comparáveis às apresentadas pelas glossopterídeas provenientes de ambientes marginais às áreas pantanosas (Quitéria, 2,95\%) ou corpos lacustres (nível 4 do Morro do Papaléo, 2,39\%), exibindo elevados níveis de tecido vegetal removido.

Considerando todos os afloramentos analisados, a proporção de folhas herbivorizadas obtida (mínimo de 7,02\% e máximo de $12,50 \%$ ) pode ser considerada muito próxima daquela encontrada em florestas subtropicais e temperadas atuais que é, respectivamente, de 7,5\% a 11\% (Labandeira, 1998). 
Esses resultados indicam um relativo aquecimento climático durante a deposição dos sedimentos da Formação Rio Bonito, em relação aos depósitos subjacentes, de modo a favorecer a herbivoria (Guerra-Sommer \& Cazzulo-Klepzig, 2000; Adami-Rodrigues \& Iannuzzi, 2001).

Os dados quantitativos associados à análise qualitativa de Adami-Rodrigues et al. (no prelo) suportam a hipótese de que o comportamento dos insetos herbívoros vem se mantendo ao longo do tempo geológico, sendo observado desde o Permiano os aspectos qualitativos de suas interações com as plantas e a intensidade de herbivoria.

\section{AGRADECIMENTOS}

Os autores expressam agradecimentos a Renata Guimarães Netto (UNISINOS) pelas significativas sugestões na análise do manuscrito; a Carlos Eduardo Lucas Vieira e Flávio Lopez (IG/UFRGS) pela colaboração na confecção das figuras e fotografias. O presente trabalho é parte integrante da Tese de Doutoramento da primeira autora, desenvolvida no Programa de Pós-Graduação em Geociências do Instituto de Geociências da UFRGS.

\section{REFERÊNCIAS}

Adami-Rodrigues, K.2003. Evidências de interações inseto-planta nos depósitos neopaleozóicos do Rio Grande do Sul. Programa de Pós-Graduação em Geociências, Universidade Federal do Rio Grande do Sul, Tese de Doutoramento. 40 p.

Adami-Rodrigues,K.; Iannuzzi, R. \& Pinto, I.D. (no prelo) Permian plant-insect interactions from a Gondwana flora of southern Brazil. Fossils and Strata, $\mathbf{5 0 .}$

Adami-Rodrigues, K \& Iannuzzi, R. 2001. Late Paleozoic terrestrial arthropod faunal and floral sucessions in the Paraná Basin: a preliminary synthesis. Acta Geológica Leopoldensia, 52/53:165179.

Albuquerque, L.F.F. \& Lopes, R.C. 1990. Estudo paleoambiental da Formação Rio Bonito na região das jazidas do Leão, Pantano Grande e nordeste da jazida do Iruí - RS, uma análise ambiental. Ciência e Natura, 12:35-39.

Ash, A.; Ellis, B., Hickey, L.J.; Johnson, K.; Wilf, P. \& Wing, S. 1999. Manual of Leaf Architecture - Morphological description and categorization of dicotyledonous and net-veined monocotyledonous angiosperms by Leaf Architecture. $1^{\mathrm{a}}$ ed. Washington DC, Smithsonian Institution Press, 65 p.

Beck, A.L. \& Labandeira, C.C. 1998. Early Permian insect folivory on a gigantopterid-dominated riparian flora from north-central Texas. Palaeogeography, Palaeoclimatology, Palaeoecology, 142:139-173.

Beck, A.L.; Labandeira, C.C. \& Mamay, S.H. 1996. Host spectrum and intensity of insect herbivory on a Lower Permian riparian flora: implications for the early sequestering of vascular plant tissues. Geological Society of America, Abstracts with Program, 28:105.

Chaloner, W.G.; Harper, J.L. \& Lawton, J.L. (eds.) 1991. The evolutionary interations of animals and plants. Philosophical Transactions of the Royal Society of London, B333:177-305.

Fergunson, D.K. 1970. The Miocene flora of Kreuzau, Western Germany. Amsterdam, North-Holland Publishin Company, $512 \mathrm{p}$.
Greenwood, D.R. 1992. Taphonomic constraints on foliar physiognomic interpretations of Late Cretaceous and Tertiary paleoclimates. Review of Palaeobotany and Palynology, 71:149-190.

Guerra-Sommer, M. 1988. Padrões epidérmicos da Flora Glossopteris na jazida do Faxinal (Formação Rio Bonito, Kunguriano, RS): implicações taxonômicas, bioestratigráficas e paleogeográficas. Programa de Pós-Graduação em Geociências, Universidade Federal do Rio Grande do Sul, Tese de Doutoramento, $375 \mathrm{p}$.

Guerra-Sommer, M. 1995. Fitofagia em glossopterídeas na paleoflora da Mina do Faxinal (Formação Rio Bonito, Artinskiano, Bacia do Paraná). Pesquisas, 22:58-63.

Guerra-Sommer, M. \& Cazzulo-Klepzig, M. 1993. Biostratigraphy of the Southern Brazilian Neopaleozoic Gondwana sequence: a preliminary palaeobotanical approach. In: INTERNATIONAL CONGRÈS DE LA STRATIGRAPHIE ET GÉOLOGIE DU CARBONIFÈRE ET PERMIEN, 12, 1991. Comptes Rendus, Buenos Aires, APA, 2:61-72.

Guerra-Sommer, M. \& Cazzulo-Klepzig, M. 2000. Early Permian palaeofloras from Southern Brazilian Gondwana: a palaeoclimatic approach. Revista Brasileira de Geociências, 30(3):486-490.

Holz, M. 1998. The Eo-Permian coal seams of the Paraná Basin in southernmost Brazil: an analysis of the depositional conditions using sequence stratigraphy concepts. International Journal of Coal Geology, 690:1-23.

Iannuzzi, R.; Marques-Toigo, M.; Scherer, C.M.S.; Caravaca, G.; Vieira, C.E.L. \& Pereira, L.S. 2003. Reavaliação da fitobiobioestratigrafia da seqüência gondvânica sul-riograndense: estudo de caso do afloramento Morro do Papaléo (Bacia do Paraná, Permiano Inferior). In: ENCONTRO SOBRE A ESTRATIGRAFIA DO RIO GRANDE DO SUL: ESCUDOS E BACIAS, 1, 2003. Anais, Porto Alegre, UFRGS, 182-185.

Jasper, A. \& Guerra-Sommer, M. 1999. Licófitas arborescentes in situ como elementos importantes na definição de modelos deposicionais (Formação Rio Bonito - bacia do Paraná-Brasil). Pesquisas, 26(1):49-58.

Labandeira, C.C. 1998. Early history of arthropod and vascular plant associations. Annual Review of Earth and Planetary Sciences, 26:329-377.

Labandeira, C.C. \& Beall, B.S. 1990. Arthropod terrestriality. In: D. Mikulic (ed.) Arthropod Paleobiology. Short courses in Paleontology 3, University of Tennessee Press, p. 215-255.

Landsberg, J. \& Ohmart, C. 1989. Levels of insect defoliation in forests: patterns and concepts. Trents in Ecology and Evolution, 4:96-100.

Lavina, E.L. \& Lopes, R.C. 1987. A transgressão marinha do Permiano Inferior e a evolução paleogeográfica do Supergrupo Tubarão no Estado do Rio Grande do Sul. Paula-Coutiana, 1:51-103.

Marques-Toigo, M. 1988. Palinologia, bioestratigrafia e paleoecologia do Neopaleozóico da bacia do Paraná nos estados do Rio Grande do Sul e Santa Catarina, Brasil. Programa de PósGraduação em Geociências, Universidade Federal do Rio Grande do Sul, Tese de doutoramento, $259 \mathrm{p}$.

McLoughlin, S. \& Drinnan, A.N. 1996. Anatomically preserved Permian Neoggerathiopsis leaves from east Antarctica. Review of Palaeobotany and Palynology, 92:207-227.

Millani, E.J. 1997. Evolução tectono-estratigráfica da bacia do Paraná e seu relacionamento com a geodinâmica fanerozóica do Gondwana sul-oriental. Programa de Pós-Graduação em Geociências, Universidade Federal do Rio Grande do Sul, Tese de Doutorado, $261 \mathrm{p}$. 
Netto, R.G. 1994. A paleoicnologia como ferramenta de trabalho na sequiência sedimentar Rio Bonito/Palermo. Programa de PósGraduação em Geociências, Universidade Federal do Rio Grande do Sul, Tese de Doutorado, 272 p.

Piccoli, A.E.M.; Menegat, T.; Guerra-Sommer, M.; Marques-Toigo, M.\& Porcher, C.C. 1991. Faciologia da sequiência sedimentar gonduânica nas folhas de Quitéria e Várzea do Capivarita. Pesquisas, 18:31-43.

Scott, A.C. 1992. Trace fossils of plant-arthropod interations. In: C.G. Maples \& R.R. West (eds.) Trace Fossils: notes for a short course, University Tennessee Press, p. 197-223.

Scott, A.C. \& Taylor, T.N. 1983. Plant/animal interactions during the Upper Carboniferous. Botanical Review, 49:259-307.

Scott, A.C. \& Titchener, F.R. 1999. Techniques in the study of plantarthropod interactions. In: T.P. Jones \& N.P. Rowe (eds.) Fossil plants and spores: modern tecniques, Geological Society, p. 310-315.

Scott, A.C.; Stephenson, J. \& Chaloner, W. 1992. Interaction and coevolution of plants and arthropods during the Palaeozoic and Mesozoic. Philosophical Transactions of the Royal Society of London, B335:129-165.
Scott, A.C.; Titchener, F. \& Collinson, M.E. 1994. Quantification and pattern of plant-insect interations in the fossil record and the problem of taphonomic bias. Palaeontological Society (Special Publication), 8:349.

Srivastava, A.K. 1987. Lower Barakar flora of Raniganj coalfield and insect/plant relationship. Palaeobotanist, 36: 138142 .

Stephenson, J. \& Scott, A.C. 1992. The geological history of insectrelated plant damage. Terra Nova, 4:542-552.

Vieira, C.E.L. \& Iannuzzi, R. 2000. Preença de Pecopteris e Asterotheca no afloramento do Morro do Papaléo, município de Mariana Pimentel, Rio Grande do Sul (Formação Rio Bonito, Eopermiano da Bacia do Paraná). Pesquisas, 27(2):49-64.

Wint, G.R.W. 1983. Leaf damage in tropical rain forest canopies. In: S.L. Sutton, C. Whitmore, C. \& A.C. Chadwick (eds.) Tropical Rain Forest: ecology and management, Blackwell Scientific Publications, p. 229-239. 